\title{
Vigilancia sanitaria de peneidos silvestres en los principales canales de marea de Tumbes, Perú
}

\author{
Sanitary surveillance of wild peneidae in the main tidal channels of Tumbes, Peru \\ Krizia Pretell-Monzón ${ }^{1}$, Katherine Saavedra-Olivos ${ }^{1}$, Alfredo Calderón-Romero ${ }^{2}$, \\ Vanessa Quevedo Alvarado², Diego Alemán de Lama ${ }^{1}$, Betsi Boada Mata ${ }^{2}$, \\ Muriel Gómez-Sánchez ${ }^{3,4}$
}

\section{Resumen}

Los canales de marea en el departamento de Tumbes, Perú, albergan diversas especies de peneidos, como Penaeus stylirostris y $P$. vannamei, esta última de gran importancia económica para el país. En 2017 se evaluaron 560 ejemplares de langostinos silvestres en dos periodos de muestreo (mayo-junio y septiembre-noviembre), provenientes de siete canales de marea para determinar la prevalencia de las enfermedades de notificación obligatoria: Síndrome de la Mancha Blanca (VSMB), Infección Hipodérmica y Hematopoyética Infecciosa (VNHHI), Necrosis Hepatopancreática (HPN), Síndrome del Taura (ST), Mionecrosis Infecciosa (VMNI) y Síndrome de la Cabeza Amarilla (VCA1) mediante la técnica del PCR. Se detectó la presencia de tres de los siete patógenos. La mayor prevalencia del estudio fue de VNHHI (6.35\%) distribuida en los siete canales de marea, seguido por HPN (2.65\%) en cinco canales de marea y VSMB $(0.55 \%)$ presente en tres canales, pero únicamente en el primer periodo de muestreo.

Palabras clave: vigilancia sanitaria; langostinos silvestres; canales de marea; prevalencia; incidencia

\section{AbSTRACT}

The tidal channels in the department of Tumbes, Peru harbor various species of penaeids, such as Penaeus stylirostris and P. vannamei, the latter of great economic importance for the country. In 2017, 560 specimens of wild prawns were evaluated in two sampling periods (May-June and September-November), from seven tidal channels to determine the prevalence of notifiable diseases: White Spot Syndrome (WSSV), Infectious

\footnotetext{
${ }^{1}$ Organismo Nacional de Sanidad Pesquera-SANIPES, Oficina Desconcentrada de Tumbes, Perú

${ }^{2}$ Facultad de Ingeniera Pesquera y Ciencias del Mar, Universidad Nacional de Tumbes, Perú

${ }^{3}$ Organismo Nacional de Sanidad Pesquera-SANIPES, Subdirección de Sanidad Acuícola, Lima, Perú

${ }^{4}$ E-mail: muriel.gomez@sanipes.gob.pe
} 
Hypodermal and Hematopoietic Infection (IHHNV), Hepatopancreatic Necrosis (NHP), Taura Syndrome (TSV), Infectious Myonecrosis (IMNV) and Yellow Head Syndrome (YHV) using the PCR technique. The presence of three of the seven pathogens was detected. The highest prevalence of the study was VNHHI (6.35\%) distributed in the seven tidal channels, followed by HPN (2.65\%) in five tidal channels and VSMB $(0.55 \%)$ present in three channels, but only in the first sampling period.

Key words: sanitary surveillance; wild shrimp; tidal channel; prevalence; incidence

\section{INTRODUCCIÓN}

El langostino blanco (Penaeus vannamei) es el recurso acuático más cultivado en el Perú (RNIA, 2018). Debido a las condiciones climatológicas que se requiere para su cultivo, el $89 \%$ de su producción se concentra en el departamento de Tumbes (RNIA, 2018), aledaño a ecosistemas de manglar y esteros (canales de marea) (Alfaro et al., 2010), debido a que actúan como fuente de abastecimiento de agua y cuerpos receptores de sus efluentes.

Estos ambientes son también hábitats naturales de diversas especies de animales, entre ellos cangrejos y langostinos, que pueden verse infectados asintomáticamente con patógenos que son perjudiciales para $P$. vannamei, $\mathrm{y}$, de ese modo, actuar como reservorio de enfermedades. La cercanía y contacto directo con los esteros hace difícil, si no imposible, la erradicación del patógeno en las áreas acuícolas afectadas (De la Peña et al., 2007). Así mismo, las enfermedades que se desarrollan en langostinos de cultivo también ponen en riesgo la salud de langostinos silvestres, dado que los patógenos pueden diseminarse en ambientes naturales a través del vertimiento de los efluentes o escapes de los mismos animales cultivados (Del Rio-Rodríguez et al., 2006; Wakida-Kusunoki et al., 2011; Lightner et al., 2012).

Los virus y bacterias son patógenos que pueden desencadenar epizootias, especialmente en langostinos de cultivo, los cuales son más vulnerables a contraer enfermeda- des cuando están bajo condiciones de estrés, especialmente como producto de las altas densidades de cultivo, baja calidad del agua y deficiencias en la nutrición, entre otros factores (Raynard et al., 2007). En el Perú, se han reportado históricamente enfermedades como la infección por Bacuolovirus penaei (BP), necrosis hipodérmica y hematopoyética infecciosa (NHHI), hepatopancreatitis necrotizante (HPN), síndrome de Taura (ST) y el síndrome de las manchas blancas (SMB) (Alfaro et al., 2010), los cuales han generado considerables pérdidas económicas al sector langostinero.

Existen pocos reportes en cuanto a la prevalencia de estos patógenos en poblaciones de langostinos silvestres de la región de Tumbes. Es por ello que el presente estudio tuvo como objetivo determinar el estado actual de las enfermedades causadas por el virus de la necrosis hipodérmica y hematopoyética infecciosa (VNHHI), virus del síndrome de la mancha blanca (VSMB), Hepatobacter penaei (HPN), virus del síndrome de Taura (VST), virus de la mionecrosis infecciosa (VMNI) y del virus de la cabeza amarilla genotipo 1 (VECA1) en peneidos silvestres que habitan los principales canales de marea de Tumbes durante 2017.

\section{Materiales y Métodos}

Se seleccionaron siete estaciones de muestreo, ubicadas en los principales canales de marea en el departamento de Tumbes, 


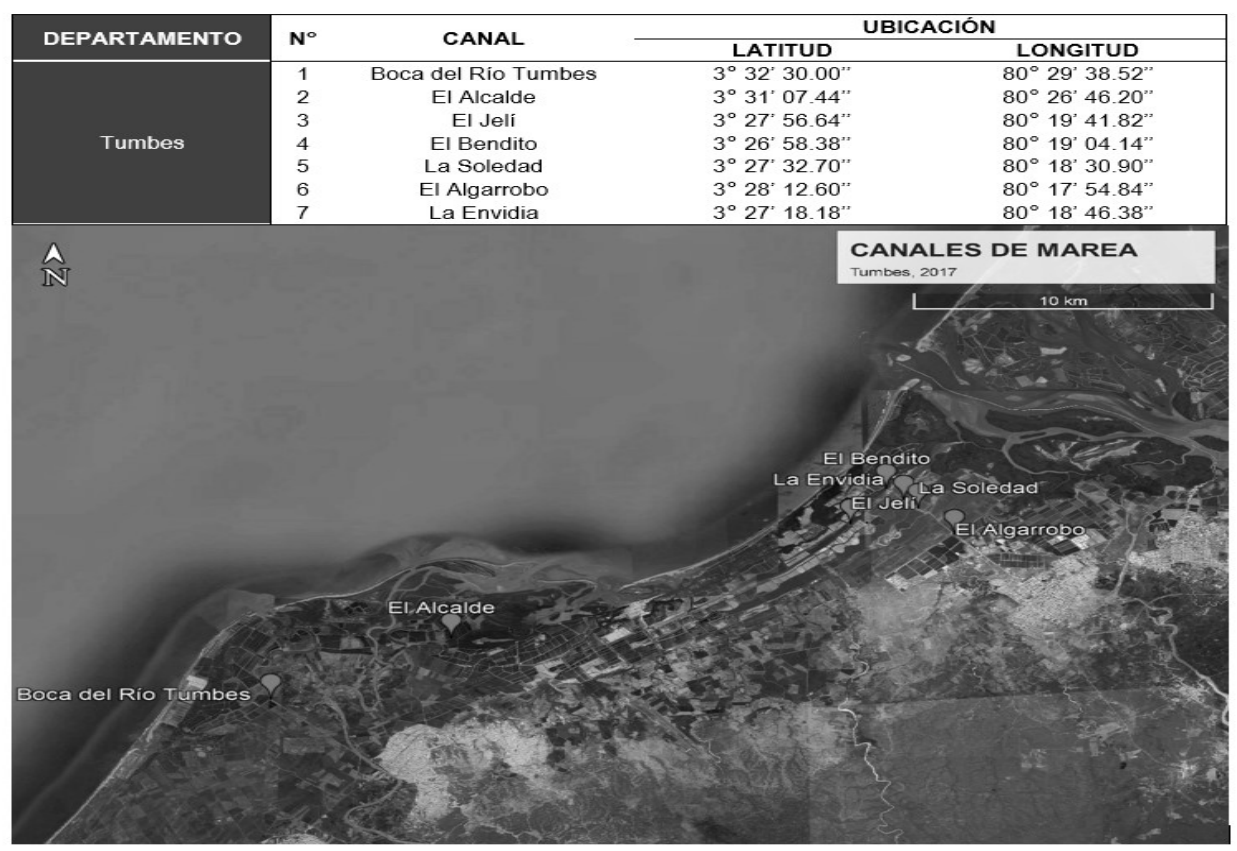

Figura 1. Ubicación geográfica de las siete estaciones de muestreo para langostinos silvestres en los principales canales de marea en Tumbes

distribuidos a lo largo de las provincias de Zarumilla y Tumbes (El Algarrobo, El Bendito, El Jelí, La Envidia, La Soledad, El Alcalde, Boca de Río de Tumbes). Las estaciones estuvieron asociadas a la toma de agua o descarga de efluentes de centros de cultivo de langostinos (Figura 1).

La obtención de los ejemplares se realizó entre mayo y noviembre de 2017. Los criterios empleados para incluir un individuo en un determinado pool fue la especie y longitud total (desde rostrum a urópodos). De esta manera, se capturaron 560 ejemplares silvestres entre $P$. vannamei (langostino blanco) y $P$. stylirostris (camarón azul), de una longitud aproximada de $1-10 \mathrm{~cm}$. La toma de muestra se realizó mediante lances de atarraya, hasta completar 20 ejemplares por canal de marea. Cada muestra fue preservada en fresco y transportada al laboratorio donde se tomaron características externas (flacidez, coloración y deformidad), talla y peso (Cuadro 2). Adicionalmente, durante los meses de setiembre y noviembre, se registró la temperatura y salinidad en los puntos de muestreo.

El muestreo en canales de marea se realizó en dos periodos: mayo y junio; y setiembre y noviembre. Los ejemplares capturados durante los meses de mayo y junio fueron agrupados en pools de 10 individuos (dos muestras por estación de muestreo) y aquellos capturados entre setiembre y noviembre en pools de 5 individuos (cuatro muestras por estación de muestreo).

Para el análisis molecular, las muestras fueron analizadas en un laboratorio privado, en donde se extrajo el hepatopáncreas para el análisis de HPN, el músculo para VNHHI y VMNI, las branquias para VST y VCA1, y los pleópodos para VSMB. La extracción de ADN se realizó mediante el método de buffer lisis $(\mathrm{NaOH}, 0.05 \mathrm{~N}$; SDS, 0.25\%) (Motte et al., 2003) y para el caso de ARN fue usado el tioisocianato de guanidina 


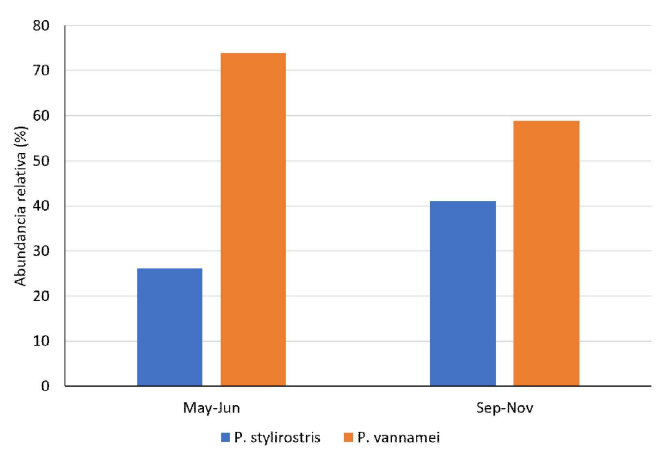

Figura 2. Abundancia relativa de los especímenes Penaeus stylirostris y Penaeus vannamei durante los dos periodos de estudio en los canales de marea de Tumbes (2017)

(Trizol ${ }^{\circledR}$, Invitrogen). La PCR se llevó a cabo bajo las recomendaciones del Manual Acuático en línea de la OIE (2017) (Cuadro 1).

El cálculo de estimación de la prevalencia y límites de confianza se realizó mediante el programa en línea Epitools (http:// epitools.ausvet.com.au), empleando un nivel de confianza del $95 \%$ y asumiendo un $100 \%$ de sensibilidad y especificidad del ensayo en dos tamaños diferentes de pool (10 y 5). Asimismo, se realizó el cálculo de la incidencia de cada enfermedad mediante la división de los resultados positivos entre el total de muestras analizadas en cada periodo de evaluación.

\section{Resultados y Discusión}

\section{Langostinos Capturados}

La mayoría de los animales capturados mostraron aparente buen estado de salud; sin embargo, algunos presentaron coloración rojiza o verduzca en los urópodos, branquias amarillas y músculo blando. El peso y talla promedio fue de $6.31 \mathrm{~g}$ y $8.88 \mathrm{~cm}$ durante el periodo de mayo y junio, mientras que en los meses de setiembre y noviembre fue de 3.47 g y $6.99 \mathrm{~cm}$ (Cuadro 2). Por otro lado, se registró una temperatura media de $25.6^{\circ} \mathrm{C}$ y una salinidad de 34.9 ups (Unidades Prácticas de Salinidad) durante la marea baja.

Debido a que se realizó un muestreo aleatorio, el número de especímenes de $P$. stylirostris y $P$. vannamei no fueron iguales. La abundancia relativa de $P$. stylirostris en la captura fue menor a la de $P$. vannamei en ambos periodos de estudio (Cuadro 3); no obstante, se observó un ligero incremento de $15 \%$ de $P$. stylitrostris en el segundo periodo (Figura 2).

La menor abundancia relativa de $P$. stylirostris podría atribuirse a factores tales como variaciones de salinidad, flujo de agua y depredación (Galindo-Bect et al., 2007), o a eventos de mortalidad ocasionadas por enfermedades como NHHI, que se caracteriza por ocasionar altas mortalidades en juveniles de esta especie, mientras que en $P$. vannamei desarrolla una enfermedad crónica, ocasionando un síndrome de deformidades y enanismo (Pantoja y Lightner, 2014).

\section{Enfermedades Prevalentes}

Los resultados de prevalencia confirman la presencia de VNHHI (6.35\%), HPN (2.65\%) y VSMB (0.55\%) en langostinos silvestres (Cuadro 4). Estos resultados difieren a lo encontrado por Alfaro et al. (2010) en la misma zona, quienes reportaron VSMB (2.75\%), HPN $(0.62 \%)$ y VNHHI $(0.31 \%)$. No se obtuvieron resultados positivos que indiquen la presencia de VST, VMNI y VCA1, al igual que Alfaro et al. (2010).

La infección con el VNHHI fue la enfermedad con mayor prevalencia en los canales de marea $(6.35 \%)$, y además presentó un amplio rango de distribución al encontrarse presente en los siete puntos evaluados (Figura 3). Estos resultados coinciden con los observados en la reserva silvestre del Golfo de California, donde la infección se diseminó 
Cuadro 1. Descripción de los iniciadores y secuencias que fueron utilizadas para el diagnóstico de las seis patologías ${ }^{1}$ en langostinos silvestres

\begin{tabular}{|c|c|c|c|c|}
\hline Patógeno & Iniciador & Secuencia & $\begin{array}{l}\text { Tamaño } \\
(\mathrm{pb})\end{array}$ & Referencia \\
\hline \multirow[t]{4}{*}{ VSMB } & F1 & TCTGGGAAATGTACAAAAA & \multirow[t]{2}{*}{653} & \multirow{4}{*}{$\begin{array}{l}\text { Mello et al. } \\
\text { (2011) }\end{array}$} \\
\hline & R1 & AGGGAAACTGTGAGAAATT & & \\
\hline & F2 & GGACATTGGAAGAGATTGA & \multirow[t]{2}{*}{412} & \\
\hline & $\mathrm{R} 2$ & GAATGCACCACTAAAGAAGA & & \\
\hline \multirow[t]{4}{*}{ VNHHI } & $\mathrm{F} 1$ & ATACAGAAGAGACGAAGACGC & \multirow[t]{2}{*}{1227} & \multirow[t]{4}{*}{ Motte (2003) } \\
\hline & $\mathrm{R} 1$ & TATCGTTGTGTTTCTGTTGCT & & \\
\hline & F2 & AGACAAAAAACTGGACAAAAT & \multirow[t]{2}{*}{551} & \\
\hline & $\mathrm{R} 2$ & CCTTGGGCTTGTTCTTGTT & & \\
\hline \multirow[t]{4}{*}{ HPN } & NHPF1 & ACG TTG GAG GTT CGT CCT TCA G & \multirow[t]{2}{*}{441} & \multirow{2}{*}{$\begin{array}{l}\text { Loy et al. } \\
\text { (1996) }\end{array}$} \\
\hline & NHPR1 & TCA CCC CCT TGC TTC TCA TTG T & & \\
\hline & NHPF2 & GCCATGAGGACCTGACATCATC & \multirow[t]{2}{*}{379} & \multirow{2}{*}{$\begin{array}{l}\text { Nunan et al. } \\
(2008)\end{array}$} \\
\hline & NHPR2 & CGTTGGAGGTTCGTCCTTCAGT & & \\
\hline \multirow[t]{6}{*}{ VST } & F1 & AGTAGACAGCCGCGCTTG & \multirow[t]{2}{*}{431} & \multirow{2}{*}{$\begin{array}{l}\text { Nunan et al. } \\
\text { (1998) }\end{array}$} \\
\hline & $\mathrm{R} 1$ & TCAATGAGAGCTTGGTCC & & \\
\hline & F2 & GGTGGGACTTAATTAATGC & \multirow[t]{4}{*}{230} & \multirow{4}{*}{$\begin{array}{l}\text { Navarro et al. } \\
\text { (2009) } \\
\text { Concepto } \\
\text { Azul (2011) }\end{array}$} \\
\hline & R2 & ACTTCAAACAGGTTATCTG & & \\
\hline & & & & \\
\hline & & & & \\
\hline \multirow{4}{*}{ VMNI } & F1 & TTAGAAAGCACAATCAGCAG & \multirow{2}{*}{382} & \multirow{4}{*}{$\begin{array}{l}\text { Concepto } \\
\text { Azul (2011) }\end{array}$} \\
\hline & $\mathrm{R} 1$ & AGGTTTCATCATTTAGTTCTCT & & \\
\hline & F2 & ATAACGTACACCCTTTGGAG & \multirow[t]{2}{*}{270} & \\
\hline & $\mathrm{R} 2$ & TGGTTCTTCCCCTGGTTC & & \\
\hline \multirow[t]{4}{*}{ VCA1 } & F1 & GACATCACTCCAGACAACATCTG & \multirow[t]{2}{*}{794} & \multirow{4}{*}{$\begin{array}{l}\text { Cowley et al. } \\
(2004)\end{array}$} \\
\hline & $\mathrm{R} 1$ & GTGAAGTCCATGTGTGTGAGACG & & \\
\hline & $\mathrm{F} 2$ & CATCTGTCCAGAAGGCGTCTATGA & \multirow[t]{2}{*}{277} & \\
\hline & R2 & ACGCTCTGTGACAAGCATGAAGTT & & \\
\hline
\end{tabular}

${ }^{1}$ virus del síndrome de la mancha blanca (VSMB), virus de la necrosis hipodérmica y hematopoyética infecciosa (VNHHI), Hepatobacter penaei (HPN), virus del síndrome de Taura (VST), virus de la mionecrosis infecciosa (VMNI) y del virus de la cabeza amarilla genotipo 1 (VECA1)

en las poblaciones silvestres de $P$. stylirostris causando el $46 \%$ de prevalencia en la zona superior, mientras que era de $26 \%$ en la zona central inferior (Pantoja et al., 1999). Además, se ha reportado $28 \%$ de prevalencia en ejemplares silvestres de $P$. vannamei capturados de las costas del Pacífico de Ecuador, Colombia y Panamá (Motte et al., 2003).
Según Pantoja y Lightner (2014), la infección por el VNHHI es una enfermedad de tipo crónica en individuos adultos de $P$. stylirostris y $P$. vannamei, a diferencia del SMB y HPN que son enfermedades agudas y catastróficas. Esto aparentemente favorece que la infección por el VNHHI sea de mayor prevalencia, ya que los langostinos 
Cuadro 2. Peso y talla promedio de los langostinos colectados en canales de marea en el periodo de mayo y junio, y en el de septiembre y noviembre

\begin{tabular}{|c|c|c|c|c|c|c|c|c|}
\hline \multirow{2}{*}{ Estación } & \multicolumn{4}{|c|}{ Peso promedio $(\mathrm{g})$} & \multicolumn{4}{|c|}{ Talla promedio $(\mathrm{cm})$} \\
\hline & May & Jun & Sep & Nov & May & Jun & Sep & Nov \\
\hline Boca del Rio Tumbes & 4.6 & 7.9 & 2.06 & 3.38 & 8.5 & 9.73 & 5.44 & 7.13 \\
\hline El Alcalde & 6.7 & 3.93 & 2.72 & 0.61 & 9.6 & 7.6 & 6.2 & 3.3 \\
\hline El Jelí & 10 & 8.04 & 2.68 & 2.99 & 10 & 10 & 6.3 & 7.65 \\
\hline El Bendito & 3.1 & 10 & 3.43 & 7.28 & 7.5 & 10 & 6.75 & 8.7 \\
\hline La Soledad & 5.1 & 2.3 & 5.64 & 2.26 & 8.8 & 6.33 & 8.45 & 6.48 \\
\hline El Algarrobo & 6.7 & 5.23 & 3.87 & 3.36 & 9.6 & 8.28 & 7.54 & 8.05 \\
\hline La Envidia & 9.7 & 5.09 & 4.93 & 3.38 & 10 & 8.38 & 7.93 & 7.88 \\
\hline Promedio por mes & 6.56 & 6.07 & 3.62 & 3.32 & 9.14 & 8.62 & 6.94 & 7.03 \\
\hline Promedio por periodo & \multicolumn{2}{|c|}{6.31} & \multicolumn{2}{|c|}{3.47} & \multicolumn{2}{|c|}{8.88} & \multicolumn{2}{|c|}{6.99} \\
\hline
\end{tabular}

Cuadro 3. Número de ejemplares silvestres de Penaeus spp capturados durante los dos muestreos (mayo-junio y septiembre-noviembre) en los canales de marea de Tumbes (2017)

\begin{tabular}{lccc}
\hline \multirow{2}{*}{ Especie } & \multicolumn{2}{c}{ Ejemplares capturados } & Total \\
\cline { 2 - 3 } & Mayo-Junio & $\begin{array}{c}\text { Septiembre- } \\
\text { Noviembre }\end{array}$ & \\
\hline P. vannamei & 207 & 165 & 372 \\
P. stylirostris & 73 & 115 & 188 \\
\hline Total & 280 & 280 & 560 \\
\hline
\end{tabular}

Cuadro 4. Prevalencia de enfermedades en langostino en los canales de marea de Tumbes. Virus de la necrosis hipodérmica y hematopoyética infecciosa (VNHHI), virus del síndrome de la mancha blanca (VSMB), Hepatobacter penaei (HPN).

\begin{tabular}{lccc}
\hline Enfermedad & Prevalencia (\%) & Límite superior (\%) & Límite inferior (\%) \\
\hline VNHHI & 6.35 & 4.41 & 8.76 \\
HPN & 2.65 & 4.25 & 1.5 \\
VSMB & 0.55 & 1.42 & 0.14 \\
\hline
\end{tabular}


Cuadro 5. Incidencia de las enfermedades encontradas en el periodo de mayo-junio (28 pools) y de septiembre-noviembre (56 pools) en langostinos silvestres provenientes de canales de marea en Tumbes

\begin{tabular}{ccccccc}
\hline \multirow{2}{*}{ Patógenos } & \multicolumn{3}{c}{ Mayo - Junio } & \multicolumn{3}{c}{ Setiembre - Noviembre } \\
\cline { 2 - 7 } & $\begin{array}{c}\text { Tamaño de } \\
\text { pool }\end{array}$ & $\begin{array}{c}\text { Pools } \\
\text { positivos }\end{array}$ & $\begin{array}{c}\text { Incidencia } \\
(\%)\end{array}$ & $\begin{array}{c}\text { Tamaño } \\
\text { de pool }\end{array}$ & $\begin{array}{c}\text { Pools } \\
\text { positivos }\end{array}$ & $\begin{array}{c}\text { Incidencia } \\
(\%)\end{array}$ \\
\hline VSMB & 10 & 3 & 10.7 & 5 & 0 & 0 \\
VNHHI & 10 & 2 & 7.1 & 5 & 29 & 51.8 \\
VST & 10 & 0 & 0 & 5 & 0 & 0 \\
HPN & 10 & 1 & 3.5 & 5 & 13 & 23.2 \\
VCA1 & 10 & 0 & 0 & 5 & 0 & 0 \\
VMNI & 10 & 0 & 0 & 5 & 0 & 0 \\
\hline
\end{tabular}

Virus del síndrome de la mancha blanca (VSMB), virus de la necrosis hipodérmica y hematopoyética infecciosa (VNHHI), virus del síndrome de Taura (VST), Hepatobacter penaei (HPN), virus de la cabeza amarilla genotipo 1 (VECA1), virus de la mionecrosis infecciosa (VMNI)

Cuadro 6. Canales de marea que abastecen con agua a los centros de cultivo de langostinos ubicados en norte, centro y sur de Tumbes

\begin{tabular}{llc}
\hline División & Estero & $\begin{array}{c}\text { Número de } \\
\text { centros de } \\
\text { cultivo }\end{array}$ \\
\hline Norte & El Algarrobo & 13 \\
& El Bendito & 3 \\
& El Jelí & 10 \\
& La Envidia & 2 \\
& La Soledad & 2 \\
Centro & El Alcalde & 1 \\
Sur & $\begin{array}{l}\text { Boca de Río } \\
\text { de Tumbes }\end{array}$ \\
& & 1 \\
\hline
\end{tabular}

sobrevivientes pueden volverse portadores del virus de por vida y transmitir la enfermedad a su progenie y a otras poblaciones mediante transmisión vertical y horizontal, perdurando de esta manera en el ambiente.

HPN, ocasionada por Hepatobacter penaei, fue la segunda enfermedad de mayor prevalencia $(2.65 \%)$. Como datos comparativos, se tiene el reporte de langostinos peneidos silvestres en México con 5-17\% de prevalencia y de $0.6-1.3 \%$ en centros de cultivo, debido a que las medidas de manejo y desinfección empleadas en estos últimos (Aguirre-Guzmán et al., 2010).

Por otro lado, el $0.55 \%$ de prevalencia del VSMB coincide con Lo y Kou (1998), quienes establecen una prevalencia de este patógeno menor de $1 \%$ en poblaciones silvestres. De acuerdo con Cuéllar-Ánjel (2013), factores de estrés tales como niveles bajos de oxígeno disuelto, valores extremos de $\mathrm{pH}$, cambios súbitos de la calidad del agua, altos niveles de sólidos en suspensión, sustancias tóxicas en el agua, ablación unilateral de los pedúnculos oculares y el desove, entre otros, son fundamentales para el desarrollo de esta enfermedad.

\section{Incidencia de Enfermedades}

El patógeno causante del VSMB solo se reportó durante el primer periodo (mayo y junio) y su distribución se limitó a tres de los siete canales de marea evaluados: Boca del Río Tumbes, La Soledad y El Algarrobo (Figura 3), obteniendo una incidencia de $10.7 \%$ (Cuadro 5), a diferencia de lo encontrado por 


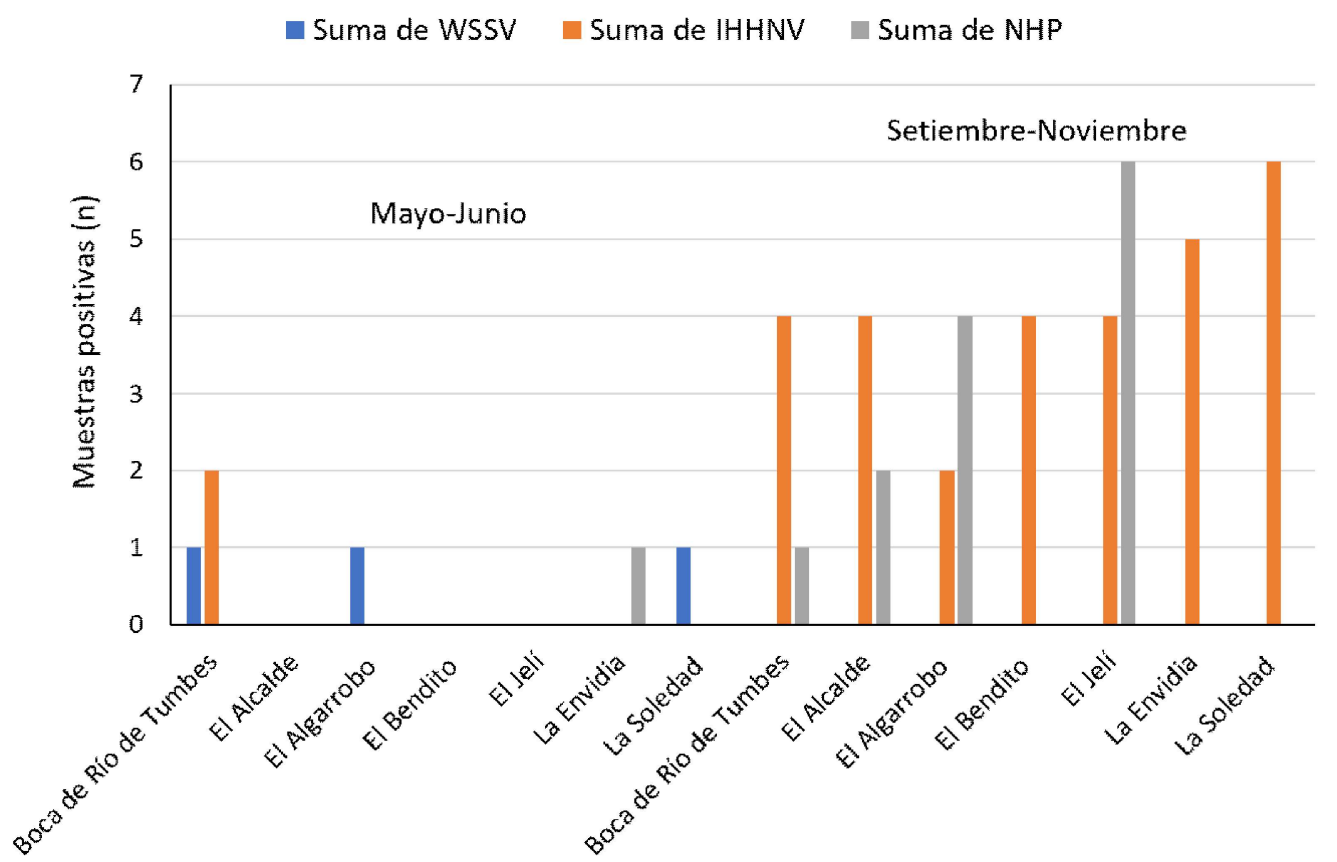

Figura 3. Número de muestras positivas a las enfermedades prevalentes encontradas en langostinos provenientes de canales de marea en Tumbes. Virus de la necrosis hipodérmica y hematopoyética infecciosa (VNHHI), virus del síndrome de la mancha blanca (VSMB), Hepatobacter penaei (HPN)

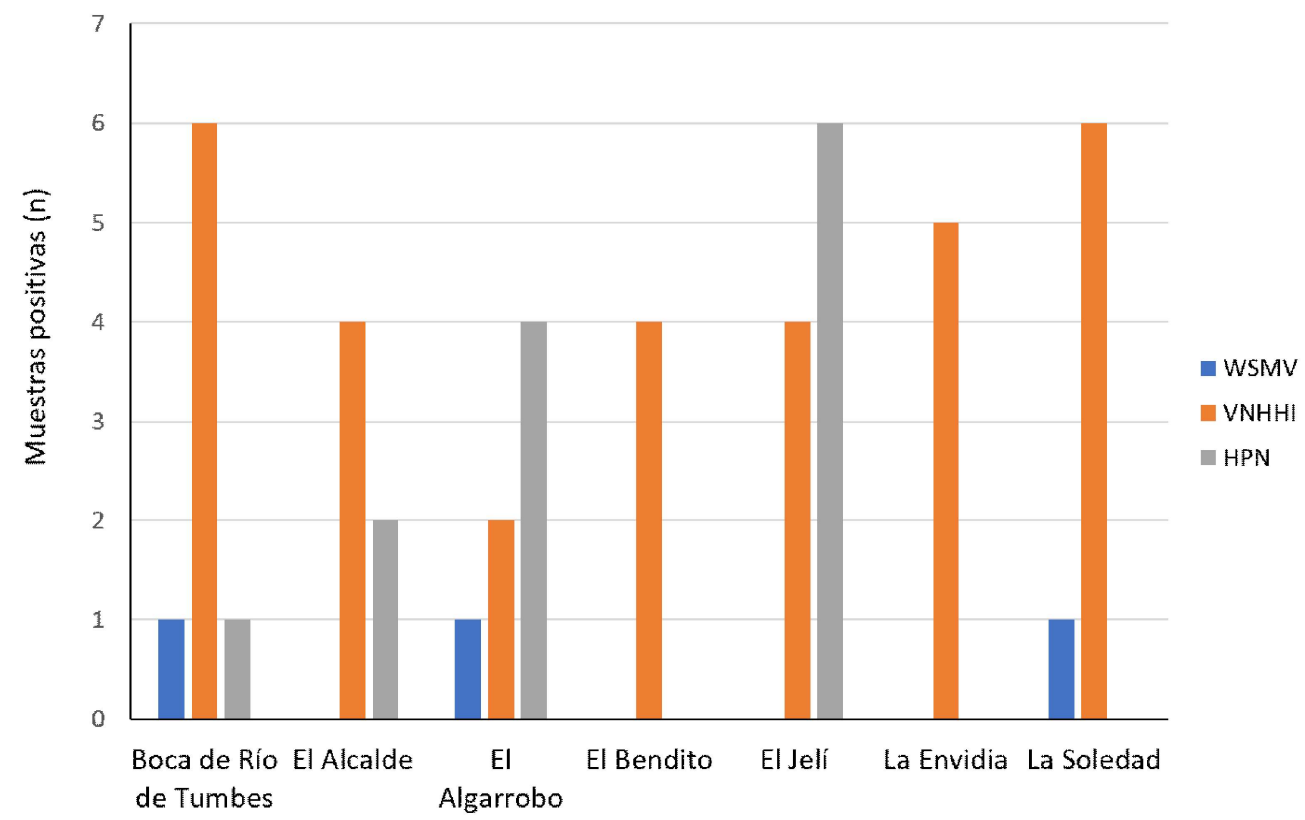

Figura 4. Número de muestras positivas a patógenos en langostinos silvestres en los canales de marea de Tumbes. Virus de la necrosis hipodérmica y hematopoyética infecciosa (VNHHI), virus del sindrome de la mancha blanca (VSMB), Hepatobacter penaei $(H P N)$ 
Alfaro et al. (2010), donde indica que este patógeno se distribuyó en casi todos los siete canales de marea evaluados a excepción de La Envidia en el mismo periodo analizado. Cabe resaltar que a pesar de que en el segundo periodo del muestreo se empleó un menor tamaño de pool (disminuyendo el factor de dilución del patógeno) no se detectó ni un espécimen positivo a VSMB.

Los patógenos VNHHI y HPN presentaron una mayor incidencia en el segundo periodo de muestreo (Figura 4), posiblemente debido a que el tamaño de pool fue menor $\mathrm{y}$, por ende, más sensible a que un patógeno sea detectado por PCR.

\section{Riesgos de Transmisión de Enfermedades}

El riesgo de transmisión de enfermedades es alto, dado que los centros de cultivo de langostino en Perú emplean sistemas de flujo de agua semi-cerrado, utilizando los canales de marea tanto como fuente de abastecimiento de agua como cuerpos receptores de sus efluentes. Son pocos los establecimientos que realizan un pretratamiento para desinfectar el agua de patógenos. De esta manera, tanto los langostinos de cultivo como los silvestres quedan expuestos a patógenos que puedan estar presentes en sistemas de cultivo o canales de marea (Raynard et al., 2007).

De acuerdo con la Figura 4, el canal de marea que presentó mayor número de resultados positivos a las enfermedades evaluadas fue El Jelí, con seis casos positivos a HPN y cuatro a VNHHI. Este canal abastece de agua a 10 centros de cultivo, siendo uno de los más importantes, luego de El Algarrobo, para los productores langostineros ubicados al norte de Tumbes (Cuadro 6).

Si bien no se pudo confirmar la infección de las enfermedades detectadas mediante métodos adicionales como histopatología, no se observaron signos clínicos externos, por lo que es muy probable que los langostinos muestreados hayan sido portadores asintomáticos de las enfermedades encontradas.

\section{Conclusiones}

- Los patógenos prevalentes en langostinos silvestres de los principales canales de marea de Tumbes son el virus de la necrosis hipodérmica y hematopoyética infecciosa (VNHHI), Hepatobacter penaei (HPN) y el virus del síndrome de la mancha blanca (VSMB).

- Los canales de marea son la principal fuente de abastecimiento de agua para los cultivos de langostino, y los tratamientos de desinfección antes de su uso son mayormente deficientes o nulos, de allí que podría considerarse que tanto langostinos de cultivo como silvestres comparten las mismas enfermedades.

\section{Agradecimientos}

El trabajo tuvo como fuente de financiamiento el Programa Nacional de Innovación para la Competitividad y Productividad - INNOVATE PERÚ Contrato N. ${ }^{\circ}$ 374-PNICP-PIAP-2014. Los autores manifiestan su agradecimiento al Organismo Nacional de Sanidad Pesquera (SANIPES) por la coordinación eficiente para el desarrollo del presente estudio.

Literatura Citada

1. Aguirre-Guzmán G, SánchezMartínez JG, Pérez-Castañeda R, Orta-Rodríguez R. 2010. Detection of necrotizing hepatopancreatitis (NHP) in wild shrimp from Laguna Madre, Mexico by a multiplex polymerase chain reaction. Thai J Vet Med 40: 337-3410.

2. Alfaro R, Guevara M, Gonzales I. 2010. Prevalencia y distribución de los principales agentes etiológicos que afectan los langostinos silvestres en Tumbes. Rev Peru Biol 17: 359-364. doi: 10.15381/ rpb.v17i3.11

3. Cuéllar-Ánjel. 2013. Enfermedad de las manchas blancas. Center for Food Security \& Public Health. 5 p. [Internet]. 
Disponible en: http://www.cfsph.iastate.edu/Factsheets/es/white-spotdisease-es.pdf

4. De la Peña LD, Lavilla-Pitogo CR, Villar CB, Paner MG, Sombito CD, Capulos GC. 2007. Prevalence of white spot syndrome virus (WSSV) in wild shrimp Penaeus monodon in the Philippines. Dis Aquat Organ 77: 175179. doi: $10.3354 /$ dao01834

5. Del Rio-Rodriguez RE, SotoRodriguez $S$, Lara-Flores $\mathrm{M}, \mathrm{Cu}$ Escamilla AD, Gomez-Solano, MI. 2006. A necrotizing hepatopancreatitis (NHP) outbreak in a shrimp farm in Campeche, Mexico: a first case report. Aquaculture 255: 606-609.

6. Galindo-Bect, Page HM, Petty RL, Hernández-Ayón JM, AragónNoriega EA, Bustos-Serrano H. 2007. Variación temporal en la abundancia de postlarvas y juveniles de camarón azul (Litopenaeus stylirostris) y camarón café (Farfantepenaeus californiensis) en el estuario del Río Colorado. Cienc Mar 33: 247-258.

7. Lightner DV, Redman RM, Pantoja CR, Tang KFJ, Noble BL, Schofield P, Mohney LI, et al. 2012. Historic emergence, impact and current status of shrimp pathogens in the Americas. J Invertebr Pathol 110: 174-183. doi: 10.1016/j.jip.2012.03.006

8. Lо CF, Кои GH. 1998. Virusassociated white spot syndrome of shrimp in Taiwan: a review. Fish Pathol 33:365-371. doi: $10.3147 /$ jsfp. 33.365
9. Motte E, Yugcha E, Luzardo J, Castro F, Leclercq G, Rodríguez J, Miranda $P$, et al. 2003. Prevention of IHHNV vertical transmission in the white shrimp Litopenaeus vannamei. Aquaculture 219: 57-70.

10. Pantoja C, Lightner, DV. 2014. Enfermedades virales. En: Morales V, CuéllarÁnjel J (eds). Guía técnica - Patología e inmunología de camarones peneidos. Panamá: OIRSA. p 99-164.

11. Pantoja CR, Lightner DV, Holtschmit HK. 1999. Prevalence and geographic distribution of IHHN parvovirus in wild penaeid shrimp (Crustacea: Decapoda) from the Gulf of California, Mexico. J Aquat Anim Health 11: 23-34. doi: $10.1577 / 1548-8667$ (1999) 011<0023:PAGDOI $>2.0 . \mathrm{CO} ; 2$

12. Raynard R, Wahli T, Vatsos I, Mortensen S. 2007. Review of disease interactions and pathogen exchange between farmed and wild finfish and shellfish in Europe. VESO Project 1655. Oslo, Norway: VESO. 459 p.

13. [RNIA] Red Nacional de Información Acuícola (RNIA). 2018. Lima: Ministerio de Producción. [Internet]. Disponible en: https://rnia.produce.gob.pe/ estadistica-y-mercado/

14. Wakida-Kusunoki AT, Amador-Del Angel LE, Carrillo Alejandro $P$, Quiroga-Brahms C. 2011. Presence of pacific white shrimp Litopenaeus vannamei (Boone, 1931) in the southern Gulf of Mexico. Aquat Invasions 6: 139142. doi: 10.3391/ai.2011.6.S1.031 